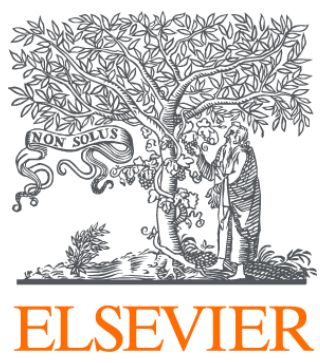

Since January 2020 Elsevier has created a COVID-19 resource centre with free information in English and Mandarin on the novel coronavirus COVID-

19. The COVID-19 resource centre is hosted on Elsevier Connect, the company's public news and information website.

Elsevier hereby grants permission to make all its COVID-19-related research that is available on the COVID-19 resource centre - including this research content - immediately available in PubMed Central and other publicly funded repositories, such as the WHO COVID database with rights for unrestricted research re-use and analyses in any form or by any means with acknowledgement of the original source. These permissions are granted for free by Elsevier for as long as the COVID-19 resource centre remains active. 


\title{
Nudges for COVID-19 voluntary vaccination: How to explain peer information?
}

\author{
Shusaku Sasaki ${ }^{\text {a,c, },}$, Tomoya Saito ${ }^{\mathrm{b}}$, Fumio Ohtake $^{\mathrm{c}, \mathrm{d}}$ \\ ${ }^{\text {a }}$ Faculty of Economics, Tohoku Gakuin University, 1-3-1 Tsuchitoi, Aoba-ku, Sendai, Miyagi 985-8537, Japan \\ ${ }^{\mathrm{b}}$ Center for Emergency Preparedness and Response, National Institute of Infectious Diseases, Japan \\ ${ }^{c}$ Center for Infectious Disease Education and Research, Osaka University, Japan \\ ${ }^{\mathrm{d}}$ Graduate School of Economics, Osaka University, Japan
}

\section{A R T I C L E I N F O}

\section{Keywords:}

COVID-19

Vaccine

Herd immunity

Behavioral public policy

Nudge

Framing effect

Autonomy

Survey experiment

\begin{abstract}
A B S T R A C T
Vaccination promotion is a crucial strategy to end the COVID-19 pandemic; however, individual autonomy should also be respected. This study aimed to discover other-regarding information nudges that can reinforce people's intention to receive the COVID-19 vaccine without impeding their autonomous decision-making. In March 2021, we conducted an online experiment with 1595 people living throughout Japan, and randomly assigned them either of one control group and three treatment groups that received messages differently describing peer information: control, comparison, influence-gain, and influence-loss. We compared each message's effects on vaccination intention, autonomous decision-making, and emotional response. We found that the influence-gain nudge was effective in increasing the number of older adults who newly decided to receive the vaccine. The comparison and influence-loss nudges further reinforced the intention of older adults who had already planned to receive it. However, the influence-loss nudge, which conveys similar information to the influence-gain nudge but with loss-framing, increased viewers' negative emotion. These messages had no promoting effect for young adults with lower vaccination intentions at baseline. Based on the findings, we propose governments should use different messages depending on their purposes and targets, such as comparison instead of influence-loss, to encourage voluntary vaccination behavior.
\end{abstract}

\section{Introduction}

Vaccination promotion is a crucial strategy to achieve herd immunity against COVID-19 and end the pandemic. Promotion measures potentially include options from simple information provision to legal mandates. However, compulsory measures are rare, and some degree of selfselection is preferred. Since herd immunity is a public good, both vaccinated and unvaccinated people benefit. Thus, people are incentivized to free-ride on the herd immunity acquired by others' vaccination uptake and avoid their own vaccination (Giubilini, 2021). If many people make this decision, there is a risk that society's vaccination rate may not reach herd immunity. Therefore, governments need to provide effective interventions to encourage people's voluntary vaccination as a cooperative action to achieve herd immunity and end the pandemic while respecting their self-selection. Behavioral economics defines nudge as "an aspect of choice architecture that alters people's behaviour in a predictable way without forbidding any options or significantly changing their economic incentives" (Thaler and Sunstein, 2009, p.6), and it will be relevant in this setting. Nudge has been used for promoting COVID-19 social distancing (Lunn et al., 2020; Sasaki et al., 2021a).

We experimentally investigated if other-regarding information nudges strengthen Japanese people's intention to receive the COVID-19 vaccine. This study contrasted older adults, who are the target of priority vaccination in lots of countries, including the U.S. (Centers for Disease Control and Prevention, 2021), U.K. (UK Government, 2021), India (Ministry of Health and Family Welfare, 2021), South Korea (Korea Disease Control and Prevention Agency, 2021), Japan (Prime Minister's Office, 2021; Ministry of Health, Labour and Welfare, 2021a), etc., with young adults, who will be eligible for vaccination later. This study's uniqueness is that we used three messages which differently describe one's own and others' decisions, and compared their effects on people's vaccination intentions, autonomous decision-making, and emotional response. Research has shown that some nudges could impede autonomy, evoke negative emotions (Allcott and Kessler, 2019; Glaeser, 2006;

\footnotetext{
* Corresponding author. Faculty of Economics, Tohoku Gakuin University, 1-3-1 Tsuchitoi, Aoba-ku, Sendai, Miyagi 985-8537, Japan.

E-mail address: ssasaki.econ@gmail.com (S. Sasaki).
} 
Loewenstein and O'Donoghue, 2006; Thunström, 2019), and potentially force people to make choices they may not wish to make. Behavioral economics calls such inconsiderate interventions sludge, not nudge (Sunstein, 2020; Thaler, 2018). Such interventions could promote the desired cooperative behavior in the short term. However, they could also reduce current cooperative behaviors and those in the long term (Damgaard and Gravert, 2018; Nafziger, 2020). Even if those interventions can promote vaccinations at present, they may decrease the levels of other infection control measures and future vaccination. Thus, this study explores nudges that promote COVID-19 vaccination while simultaneously considering people's autonomous decision-making and emotional response. This objective also follows the least restrictive alternative in public health, which states that we must select measures that place the least restrictions on individual freedom and rights, to achieve a public good, including herd immunity (Childress et al., 2002; Giubilini, 2021).

\section{Literature review}

Nudges have been used to promote prosocial behaviors, including energy-saving, charitable donations, tax-paying, etc. Since the public goods supplied by the prosocial behaviors have positive externalities, people have incentives to free-ride on others' prosocial behaviors (Becker, 1974). This issue is common in vaccination scenarios. Additionally, while energy-saving efforts help improve the global environment by reducing carbon dioxide emissions, they have personal benefits like cost-savings on bills. This feature is also common to vaccination uptake, which has both the society-wide benefit of preventing the spread of infection, achieving herd immunity, and ending the pandemic and the individual benefit of preventing onset, severity, and personal infection.

Among nudges, defaults and information nudges have been effective in promoting prosocial behaviors. The former encourages people to perform a socially desirable option by making it the default setting. For example, in countries where the default setting is the willingness to donate organs, and people need to opt out when they do not wish to donate, the proportion of those willing to donate is extremely high compared to that in countries where this is not the case (Johnson and Goldstein, 2003). The latter nudge stimulates people's motivations and encourages people to perform an ideal choice by devising the message content and framing. Other-regarding nudges, which this study focuses on, are one type of information nudge. Behavioral economics call nudges informing others' decisions and behaviors, in particular, "social comparison nudges." Several experimental studies have shown that social comparison nudges effectively promote prosocial behaviors, including energy-saving, charitable donations, and tax-paying (Allcott, 2011; Hallsworth et al., 2017; Shang and Croson, 2009). Other informational nudges express the same content in different framings. Typical framing includes gain versus loss and self versus group. These framing effects have been tested in promoting health behaviors primarily (Detweiler et al., 1999; Schneider et al., 2001) and promoting social distancing during this pandemic (Capraro and Barcelo, 2020; Jordan et al., 2021; Sasaki et al., 2021a). Social distancing has the collective benefit of preventing the spread of infection to others and the individual benefit of preventing personal infection. These are similar to the characteristics of prosocial behavior and vaccination uptake. On the other hand, the results are mixed as to which framing is more effective.

Although defaults and information nudges have been effective in encouraging seasonal influenza vaccinations, etc., it is still unclear whether they can be applied to COVID-19 vaccinations. Chapman et al. (2016) showed the vaccination rate of the flu increased by scheduling the vaccination date and time in advance and recommending it. However, the rate of unannounced cancellations also increased, placing a heavy burden on the medical institution. Since the COVID-19 vaccine cannot be refrozen once thawed, it must be used within a short validity period (The U.S. Food and Drug Administration, 2021), making it vulnerable to a high rate of no-show cancellations. Previous studies on framings have shown that the loss framing is slightly more effective in vaccination promotion than the gain framing (Nan, 2012a, 2012b, 2012b). However, a recent study reported that neither framing affected the intention to receive the COVID-19 vaccine (Chen et al., 2021). Additionally, one study reported that the individual framing was more effective for the flu vaccination (Pittman, 2020), while another study supported the collective framing (Kelly and Hornik, 2016).

Two recent field experiments have shown that emphasizing "vaccine ownership" is effective for both the flu and COVID-19 vaccine. Milkman et al. (2021) found that the message "Full shot reserved for you" increased the proportion of people who received the flu vaccine. Dai et al. (2021) found that the message "a COVID-19 vaccine has just been made available to you ..." increased the proportion of people who received the COVID-19 vaccine. By receiving these messages, people may feel reassured that their vaccine is ready and think that if they do not receive the vaccine, it may go to someone else. Their vaccination uptake may be promoted by the sense of loss through endowment effect (Kahneman et al., 1990). Japanese local governments sent coupons for free COVID-19 vaccines to people before accepting vaccination reservations (although the flu requires a fee in Japan). This advance mailing may have the similar effect of making people feel that their vaccine was secured.

In our view, an essential feature of the above effective messages was that they do not focus on the vaccine's efficacy/effectiveness in preventing infection, disease onset, or severe disease, nor on the benefits to individuals or society as the consequences. Therefore, the policy strength lies in the fact that the message is available regardless of the effect types and degrees.

COVID-19 vaccines were newly developed. In general, at the stage of vaccine approval, some elements of vaccine efficacy are clarified through randomized trials in experimental settings. Other elements of vaccine efficacy/effectiveness will be newly clarified through investigations using field data after approval. In the case of COVID-19 vaccines, the vaccine's efficacy in preventing disease onset was confirmed first, followed by the efficacy/effectiveness in preventing infection and severe disease. However, the appearance of mutant strains may change the type and degree of efficacy/effectiveness (see the review by Tregoning et al., 2021). In fact, when we conducted this study, the Japanese government announced that the COVID-19 vaccine could have an onset-prevention effect but did not actively announce the possibility that it would also have an infection-prevention effect (Prime Minister's Office, 2021; Ministry of Health, Labour and Welfare, 2021a,b). If we can encourage vaccination by emphasizing factors different from the vaccine's performance, this has great policy significance in vaccine promotion for emerging infectious diseases, despite some uncertainties.

This study adds new insights to this context by using other-regarding nudges. The nudges focus on one's own and others' decisions, which are different elements from the vaccine's performance itself. As mentioned above, the social comparison nudge, one type of other-regarding nudges, has been found to promote various prosocial behaviors, and thus we can expect that this nudge will be similarly effective in COVID-19 vaccination promotion. Although this nudge has another potential to enhance free-riding and weaken vaccination intentions (Ibuka et al., 2014), Moehring et al. (2021) found in a large-scale survey of 23 countries that providing information about others' COVID-19 vaccination intentions strengthened survey participants' intentions. Latkin et al. (2021) found that social norms are strongly associated with people's trust in the COVID-19 vaccine.

However, social-comparison nudges still have scope for well-being improvements. Traditionally, the nudges have been expected to have only the effect of making people's behavior better for themselves and society by helping them make decisions in line with their preferences. This view assumes that the nudges will not harm people. On the other hand, social-comparison nudges promote behavioral changes, by making people aware of negative emotions from not behaving in the same way as others. If this prompts those who wish to receive the COVID-19 
vaccine but have difficulty in doing so on their own, their well-being will improve overall. However, those who have made a firm decision not to receive it or those unable to receive it for health reasons will obtain additional negative emotions when receiving the nudge, and then their well-being will deteriorate. Furthermore, although nudges with negative emotions could promote the desired cooperative behavior in the short term, they could reduce current cooperative behaviors and those in the long term (Damgaard and Gravert, 2018; Nafziger, 2020). Even if those nudges promote COVID-19 vaccination currently, they may decrease the levels of other infection control measures and future vaccination. Therefore, it is essential from a policy perspective to improve nudges so that people do not have negative emotions against them.

There has been a growing body of research on the emotional costs of information nudges (Allcott and Kessler, 2019; Thunström, 2019; Yan and Yates, 2019): however, the emotional costs have not yet been explicitly considered in COVID-19 vaccination, to the best of our knowledge. The least restrictive alternative will prefer a nudge that recommends vaccination with respect for people's autonomous decision-making and as little emotional burden as possible. This study adds to the literature by simultaneously considering the impacts of other-regarding nudges on vaccination intention, autonomous decision-making, and emotional burden.

\section{Experimental design}

\subsection{Overview}

We conducted a pre-registered, online experiment with a Japanese nationwide sample over a 3-day period from March 16-18, 2021. Since vaccinations for ordinary people had not begun in Japan at the time of conducting this experiment, we evaluated the impacts of nudge-based messages for participants who did not yet receive the vaccine, including those with strong intentions to receive the vaccine and those with weak intentions.

We commissioned a local survey company, MyVoiceCom Co. Ltd., to manage the experiment. Around one million adults living throughout Japan register with this company as response monitors. We set our experimental participants as monitors aged 65-74 years and 25-34 years to compare the nudges' effects on older adults, who are at higher risk of severe disease and can be vaccinated earlier, with the effects on the young adults, who are at lower risk and can be vaccinated later. In Japan, vaccination for healthcare workers started in February 2021, and that for ordinary older adults (65 years and older) started in April. The vaccination schedule for people except those listed above had not yet been determined at the time of this experiment (Ministry of Health Labour and Welfare, 2021b). We collected 800 responses from people between 65 and 74 years old and 800 from people between 25 and 34 years old, pre-assigning the monitors to be sex-equal in each generation. Respondents received 60 Japanese Yen (JPY, hereafter) as a reward (One US dollar was approximately equivalent to 108 JPY in March 2021). There were 798 and 797 valid responses, respectively. We excluded five people in the process of calculating the outcome variable, and we will explain the details later. Older adults who join online surveys must have access to the Internet. The rate of Internet use among Japanese older adults increased annually. However, their rates were lower than those of the younger generation $(90.5 \%$ in their $60 \mathrm{~s}$ and $74.2 \%$ in their 70 s according to Ministry of Internal Affairs and Communications (2019)). Thus, those who registered with the online survey company might maintain a higher cognitive function among the same age group in a general population. On the other hand, such older adults were an appropriate target for this study because they were more likely to make vaccination decisions independently (Kan and Zhang, 2018).

We obtained ex-ante approval from the ethics committee of Graduate School of Economics, Osaka University, Japan. We also registered the experimental design with the AEA RCT Registry (Sasaki et al., 2021b). Since our sampling procedure did not directly consider the composition of prefecture residence, our sample is not nationally representative (although their residences were located throughout Japan and it is nation-wide sample). The procedure also did not guarantee random sampling within each prefecture, and thus our estimations used standard errors that were robust at the prefecture-level.

We additionally introduce Japan's situation regarding COVID-19 and vaccines. As of March 16, when we started this experiment, the cumulative number of new COVID-19 infections was 449,814, and the cumulative number of deaths was 8690 (Japan Broadcasting Corporation, 2021); divided by the total population of Japan of 120.02 million (as of January 1,2020 ), the infection rate was $0.36 \%$, and the death rate was $0.0069 \%$. Although these levels were low on an international scale, Japan's healthcare delivery system has been strained at the above levels due to the insufficient number of hospital beds for severe COVID-19 cases. On the other hand, under the current law, Japan has difficulty in implementing compulsory interventions, including lockdown. Therefore, non-compulsory interventions have been implemented, including requesting people to stay at home and stores to close or shorten business hours. However, as the pandemic continued, it became difficult to control the infection situation through these measures.

In Japan, public subsidies for the HPV vaccine started in 2010 (Hanley et al., 2015; Ikeda et al., 2019). Then, around 70\% of girls born between 1994 and 1999 received it. However, in June 2013, the Ministry of Health, Labour, and Welfare announced refraining from actively recommending vaccination for the HPV vaccine, following repeated media coverage of various symptoms related to this vaccine and subsequent lawsuits. Consequently, the HPV vaccination rate dramatically decreased and almost halted. There may still be a certain proportion of Japanese people who have strong hesitancy against vaccines. To facilitate the smooth implementation of the COVID-19 vaccine in Japan, it is crucial to explore interventions that can increase the number of people willing to receive it while not impeding the emotions of those who do not wish to participate.

\subsection{Nudge-based messages}

We randomly assigned the 1595 respondents to one of four groups. After first presenting attribute questions on sex, age, and prefecture of residence and questions related to the COVID-19 vaccine, we displayed the assigned message. The messages for each group are shown in Fig. 1. Explanations on the efficacy of the COVID-19 vaccine, adverse reactions, and how to deal with adverse reactions were the same for all groups. We created the explanations based on the Japanese actual vaccination program (The Ministry of Health, Labour and Welfare, 2021a; Prime Minister's Office, 2021) to have respondents imagine vaccination situations in detail and prevent inconsistency between their experimental choices and real behaviors (Sheeran and Webb, 2016).

For the three treatment groups, we displayed each nudge-based message in addition to the above common explanations. Group A conveyed the proportion of people willing to receive the COVID-19 vaccine. Specifically, the message for older (young) adults was "7-8 (6-7) out of 10 people in your age group answered they would receive this vaccine." These statistics were from another nationwide survey, which we conducted in January 2021 (Sasaki et al., 2021c). The survey presented hypothetical scenarios with different numbers of new COVID-19 infections and different vaccination rates in society and ascertained vaccination intentions in each scenario. The results showed that $71-81 \%(59-70 \%)$ of older adults (young adults) were willing to receive the vaccine in those scenarios. We called these messages social-comparison nudges (in short, comparison). The Literature Review showed that this message promotes various prosocial behaviors. When people receive information on the decisions and behaviors of others, they will perceive the others' choices as social norms or as the right choices (Deutch and Gerard, 1955; Fehr and Schmidt, 1999) and will prefer to make the same decisions as others. Therefore, the comparison nudge is predicted to increase the respondents' COVID-19 vaccination 
Control group

- This vaccine has been shown to be effective in preventing the onset of COVID-19.
- In other words, vaccination can reduce the likelihood of you developing COVID-19 when
you are infected.
- Vaccination may cause fever and pain and swelling in the vaccinated arm.
- In rare cases, adverse reactions of anaphylaxis may occur; however, it has been shown
that these reactions are not a serious problem if handled appropriately. Vaccination sites in
Japan are prepared to handle these reactions appropriately.

Treatment group A: Comparison nudge

(Top for older adults, Bottom for young adults)

- This vaccine has been shown to be effective in preventing the onset of COVID-19.
. In other words, vaccination can reduce the likelihood of you developing COVID-19 when
you are infected.
- Vaccination may cause fever and pain and swelling in the vaccinated arm.
- In rare cases, adverse reactions of anaphylaxis may occur, however, it has been shown
that these reactions are not a serious problem if handled appropriately. Vaccination sites in
Japan are prepared to handle these reactions appropriately.
$7-8$ out of 10 people in your age group
answered they would receive this vaccine.

- This vaccine has been shown to be effective in preventing the onset of COVID-19.

- In other words, vaccination can reduce the likelihood of you developing COVID-19 when you are infected.

- Vaccination may cause fever and pain and swelling in the vaccinated arm.

- In rare cases, adverse reactions of anaphylaxis may occur; however, it has been shown that these reactions are not a serious problem if handled appropriately. Vaccination sites in (n)

6-7 out of 10 people in your age group answered they would receive this vaccine.

Treatment group B: Influence-gain nudge

- This vaccine has becn shown to be effective in preventing the onset of COVID-19.
. In other words, vaccination can reduce the likelihood of you developing COVID-19 when
you are infected.
. Vaccination may cause fever and pain and swelling in the vaccinated arm.
- In rare cases, adverse reactions of anaphylaxis may occur, however, it has been shown
that these reactions are not a serious problem if handled appropriately. Vaccination sites in
Japan are prepared to handle these reactions appropriately.
The more people who receive this vaccine,
the more people who have an intention to do so.
Your vaccination uptake can encourage
the vaccination uptake of the people around you.

Treatment group C: Influence-loss nudge

. This vaccine has been shown to be effective in preventing the onset of COVID-19.
. In other words, vaccination can reduce the likelihood of you developing COVID-19 when
you are infected.
. Vaccination may cause fever and pain and swelling in the vaccinated arm.
. In rare cases, adverse reactions of anaphylaxis may occur; however, it has been shown
that these reactions are not a serious problem if handled appropriately. Vaccination sites in
Japan are prepared to handle these reactions appropriately.
The more people who receive this vaccine,
the more people who have an intention to do so.
If vou do not receive the vaccine,
the people around vou also may not do so.

Fig. 1. Messages.

intentions. On the other hand, this message is also predicted to drive free-riding and lower vaccination intentions. People may think that if many others are getting vaccinated, there is no need to get vaccinated themselves. Which of these two effects will emerge needs to be empirically confirmed. Previous vaccination studies have reported mixed results (Hershey et al., 1994; Ibuka et al., 2014; Sato and Takasaki, 2019): however, Moehring et al. (2021) used an international survey to support the promotion effect for the COVID-19 vaccination context. Since the effect of the majority size also depends on the first and second predictions, which of the messages for older and younger respondents is more effective needs to be confirmed empirically.
The above study of Moehring et al. (2021) used information on others' intentions, while many previous studies have used information on their behaviors. To the best of our knowledge, no studies directly compared the effect of intentional information with behavioral information. However, if many people imagine that few people with intentions take action, the effect of intentional information may be smaller. Further, if the intentional information still has a facilitating effect, it is likely to support the effectiveness of the comparison nudge. It is also useful from a policy perspective because we are able to survey to obtain intentional information before vaccination has begun and vaccination behavior is observed, as in this context.

Groups B and C focused on respondents' own vaccination behaviors possibly influencing others. This assumed that simple social-comparison nudges strengthen vaccination intentions. Our pre-survey analysis found that as the vaccination rate of the same age group increased, the vaccination intention of the respondents also increased (Sasaki et al., 2021c) and supported the assumption. This type of message is expected to stimulate people's pure altruism (Andreoni, 1990) and social image (Bénabou and Tirole, 2006), increasing their willingness to be vaccinated. Purely altruistic people who care about the well-being of others will be motivated by realizing that their vaccination uptake will encourage others around them to be vaccinated, thus saving the others' lives. Additionally, those who care about social image will be motivated by realizing that encouraging others' vaccination uptake will enhance their own reputation from others. Organizational psychology suggested people prefer to influence others (Bolino, 1999). Another experimental study reported that people's disaster evacuation intentions increase significantly when receiving messages informing their own evacuation behavior can promote those of others (Ohtake et al., 2020). Using this type of message can make people shift their attention from the negative emotion of not following social norms to the positive emotion of influencing others and society. This message also can avoid the concern of free-riding by others' vaccination information.

The message for group B was "Your vaccination uptake can encourage the vaccination uptake of the people around you." Group C expresses the same content as group B using loss-framing: "If you do not receive the vaccine, the people around you may also not do so." We call the former gain-framed social influence nudge (influence-gain) and the latter loss-framed social influence nudge (influence-loss).

Tversky and Kahneman's $(1979,1981)$ prospect theory states that people's choices and behaviors depend on whether they are framed in terms of gain or loss, even if their substance is essentially equivalent. People are generally loss-averse, and the change in value in the loss domain is perceived to be approximately twice as large as the gain domain change (Tversky and Kahneman, 1991, 1992). Thus, theoretically, their choices and behaviors are more likely to alter when the message encouraging behavioral change is loss-framed than gain-framed. However, their effectiveness empirically depended on contexts (Detweiler et al., 1999; Hameleers, 2021; Schneider et al., 2001). Heffner et al. (2020) reported that both gain and loss framings promote social-distancing intention, while only the loss framing generates negative emotions. Therefore, compared to the gain framing, the loss framing will place a heavier emotional burden on the viewer and inhibit their autonomous decision-making in the context of vaccination.

We adjusted the wording of the messages to be more natural in the native language, Japanese, so that the messages would be applicable in actual policies. Consequently, for example, the gain-framed message and the loss-framed one were phrased differently. On the other hand, the authors confirmed that the gain-framed one were understood to mean "if you receive the vaccine, the people around you may also do so." We also asked local government staff to confirm this meaning. For readers' reference, we added the original Japanese messages to the supplementary file.

However, it is true that the wording of the three nudge-based messages were not in complete contrast to each other. Therefore, when we found some differences between the message effects, we could not 
interpret that the cause was only the elements themselves (social comparison, gain-framing, loss-framing). We need to note that this study measured and compared the entire messages' effects, including those elements and other differences in wording.

Here, we assumed the respondents read the assigned message with a certain degree of thoroughness, based on the following efforts. We set a screen to display the assigned message only and they were unable to proceed to the next page until at least $10 \mathrm{~s}$ had passed, although we did not directly check whether they had read the message or not. Additionally, we displayed the assigned message again on the next page where they answered the question measuring primary outcomes. Furthermore, at the beginning of this experiment, we set a question to ascertain whether they skipped over other descriptions or not (Miura and Kobayashi, 2019). We displayed a caution message to those who skipped over them (about 6.6\% of all respondents), empirically controlling for them.

We also assumed that most respondents were aware of anaphylaxis and other adverse reactions, while they did not understand the details at the time of this experiment. The details were available on the websites of the Prime Minister's Office (2021), the Ministry of Health, Labour and Welfare (2021a), and local governments. However, to our question on COVID-19 vaccine information exposure, $85.4 \%$ and $38.8 \%$ of the respondents answered recently seeing the vaccine information on TV and in newspapers and magazines, respectively. In comparison, only 5.2\% and $9.8 \%$ of the respondents saw it on the above governments' homepages.

\subsection{Outcome measures}

\subsubsection{Primary outcomes: vaccination intentions}

Our primary outcomes included 1) one variable indicating whether or not respondents will receive the COVID-19 vaccine when offered free of charge (free-vaccine), and 2) another variable indicating their willingness to pay for it (WTP). In Japan's actual vaccination program, people's out-of-pocket costs are zero, and the former variable provides policy-important information. The WTP is the maximum amount that people are willing to pay for the vaccine. Those who place a higher value on it will be likely to express a higher WTP. The WTP has been used as an indicator of the acceptability or willingness to be vaccinated also in the context of COVID-19 vaccines (Berghea et al., 2020; Cerda and García, 2021; Wong et al., 2020). The WTP informs us how many people will receive the vaccine when offered at a specific price. It also informs what price (or subsidy) governments need to put on the vaccine to secure a specific target vaccination rate.

As the first step to measure these indicators, we displayed with the assigned message the following question: "Suppose you can receive this vaccine without having to pay out-of-pocket, will you visit the vaccination site and receive it?" Our analysis used this answer as free-vaccine.

For the second step, those who answered that they would receive the free vaccine proceeded to the question on the payment setting (left panel, Fig. 2), while those who answered that they would not, proceed to the question on the receipt setting (right panel). The questions had a Multiple Price List format, often used to calculate WTP (Andersen et al., 2006). We defined WTP as the midpoint of the amounts around the switching point. For example, a respondent answers they will receive the vaccine if they need to pay $8000 \mathrm{JPY}$ or less, while they will not if they need to pay 10,000 JPY or more; the WTP is $9000 \mathrm{JPY}$. This means they want to receive the vaccine even if they need to pay 9000 JPY. However, if another respondent answers that they will not receive the vaccine even if they can receive 15,000 JPY or less, but they will do it if they receive 20,000 JPY or more; their WTP is $-17,500$ JPY. This means they do not want to get vaccinated unless they receive $17,500 \mathrm{JPY}$ or more. The WTP for those who answer that they will receive the vaccine under all choices, including the maximum amount of 30,000 JPY, becomes 35, 000 JPY. The WTP of those who answer that they will not receive it under all choices becomes -35,000 JPY.

This calculation procedure for WTP assumes that each respondent has only one switching point. This assumption is reasonable to a certain degree. Under the payment setting, once a respondent switches from receiving the vaccine to not receiving it, it is unlikely that they will switch back to receiving it when they need to pay a higher amount. Similarly, under the receipt setting, once the choice has switched from not receiving the vaccine to receiving it, it is unlikely to switch back to not receiving it when a higher amount of reward is available. However, there are rare cases of people with more than two switching points, which was the case only for five respondents in this experiment $(0.25 \%$ of all respondents). Since the above calculation procedure cannot calculate their WTP, we excluded the five respondents with more than two switching points from our data analysis.

The related studies showed that the WTP amounts for COVID-19 vaccines lie in the range of around $2500 \mathrm{JPY}$ to 25,000 JPY: 3315.6 JPY (\$30.7) in a Malaysian study (Wong et al., 2020), 2559.5-25,600.3

\begin{tabular}{|c|c|c|}
\hline & $\begin{array}{l}\text { I wish } \\
\text { to receive } \\
\text { the vaccine. }\end{array}$ & $\begin{array}{l}\text { I do not wish } \\
\text { to receive } \\
\text { the vaccine. }\end{array}$ \\
\hline When I need to pay $¥ 0$ & 0 & 0 \\
\hline When I need to pay $¥ 1,000$ & 0 & 0 \\
\hline When I need to pay $¥ 3,000$ & 0 & 0 \\
\hline When I need to pay $¥ 5,000$ & 0 & 0 \\
\hline When I need to pay $¥ 8,000$ & 0 & $\mathrm{O}$ \\
\hline When I need to pay $¥ 10,000$ & 0 & 0 \\
\hline When I need to pay $¥ 15,000$ & 0 & 0 \\
\hline When I need to pay $¥ 20,000$ & 0 & 0 \\
\hline When I need to pay $¥ 30,000$ & 0 & 0 \\
\hline
\end{tabular}

\begin{tabular}{|l|l|l|c|}
\hline \multicolumn{1}{|l|}{} & & $\begin{array}{c}\text { I wish } \\
\text { to receive } \\
\text { the vaccine. }\end{array}$ & $\begin{array}{c}\text { I do not wish } \\
\text { to receive } \\
\text { the vaccine. }\end{array}$ \\
\hline When I can receive $¥ 0$ & $\rightarrow$ & 0 & 0 \\
\hline When I can receive $¥ 1,000$ & $\rightarrow$ & 0 & 0 \\
\hline When I can receive $¥ 3,000$ & $\rightarrow$ & 0 & 0 \\
\hline When I can receive $¥ 5,000$ & $\rightarrow$ & 0 & 0 \\
\hline When I can receive $¥ 8,000$ & $\rightarrow$ & 0 & 0 \\
\hline When I can receive $¥ 10,000$ & $\rightarrow$ & 0 & 0 \\
\hline When I can receive $¥ 15,000$ & $\rightarrow$ & 0 & 0 \\
\hline When I can receive $¥ 20,000$ & $\rightarrow$ & 0 & 0 \\
\hline When I can receive $¥ 30,000$ & & & 0 \\
\hline
\end{tabular}

Fig. 2. Willingness to Pay for Vaccine. (left for payment setting, right for receipt setting). 
JPY (\$23.7-237.04) in a Romanian study (Berghea et al., 2020), and 25, 056 JPY (\$232.0) in a Chilean study (Cerda and Garacia, 2021). We set the payment setting amounts so they would cover the above range and not be too much of a burden to answer. We accordingly set those of the receipt setting. Appendix Table A shows each group's WTP distributions.

In our view, WTP may be under-reported by the fact that the COVID19 vaccine was offered for free in Japan's vaccination program. For example, suppose respondents imagined their answers might influence governments' decisions on the future price of the vaccine or subsidies. In that case, their WTP would approach zero or be negative in anticipation of it being offered at a lower price or receiving subsidies (On the other hand, if they imagined an unstable vaccine supply and believed that reporting a high WTP in this survey would ensure early and reliable access to vaccinations, WTP would be over-reported. However, this possibility was low because our question did not set the condition that the vaccine supply was unstable and it explained that people can receive the vaccine if they chose to do so). Our question included the receipt setting as well as the payment setting to account for the possibility of under-reporting. Furthermore, even if WTP was under-reported, it should not critically influence the nudges' effects, which we evaluated using RCT. Since under-reporting occurred equally in the randomized four groups, we estimated the nudges' effects as conditional on that possibility.

\subsubsection{Secondary outcomes: autonomy and emotional burden}

We used secondary outcomes to examine whether adding nudgebased messages inhibited respondents' autonomous decision-making and generated negative emotions compared to the common explanations in the control group. After the WTP question, we presented the statement, "Regarding the previous question and vaccine explanations, how much of each of the following applies to you?": 1) "Did you want to receive the vaccine voluntarily?" (voluntary), 2) "Did you think you were being forced to receive the vaccine?" (forced), 3) "Did you feel distressed when you received the explanation of the vaccine?" (distressed), and 4) "Did you feel that the explanation of the vaccine needed to be improved?" (should be improved). The questions were rated on a fivepoint scale. We defined the first two as degree of autonomous decision-making indicators and the second two as degree of the emotional burden indicators.

We created these questions to ascertain autonomy and emotional burden in the context of COVID-19 vaccinations. One related research created specific context-based indicators to measure the acceptability of nudges (Yan and Yates, 2019), and we followed that approach. When doing so, we referred to research in end-of-life care, which has long focused on patients' autonomous decision-making (Ngo-Metzger et al., 2008) and asked researchers in this field to review our questions.

\subsection{Descriptive statistics}

Appendix Table B shows the descriptive statistics for the older and young respondents. The distributions of age, sex, marital status, family structure, years of education, and household annual income were almost balanced within the same age group, while our estimations directly controlled for these variables since there were a few differences in the proportions of respondents living together aged 65 or older and not answering income information.

We used the control group, compared older and younger respondents, and found that the proportions of those who were married, separated or bereaved, or living together aged 65 or older were higher among the older respondents. On the contrary, the younger respondents had a larger number of family members living together and longer educational years.

\section{Results}

\subsection{Effects on vaccination intentions}

First, we presented vaccination intention levels in the control group. The proportion of older respondents willing to receive the free vaccine was $84.4 \%$, which was higher than for young adults, at $67.0 \%$. The average WTP was 427.1 JPY among older adults and -3300.0 JPY among the young.

Fig. 3 shows the effects of nudge-based messages on vaccination intentions, by setting the control group as a baseline and performing regression analysis without any covariates. We used robust standard errors for 47 prefectures of residence (we obtained similar results when we used robust standard errors for 9 areas of residence, which is a broader regional category). The messages were effective for older respondents. In group B with the influence-gain nudge, the proportion of older adults willing to receive the free vaccine increased by around $7 \%$ ( $p<.05$, Cohen's $\mathrm{d}=.21$ ) compared to the control group, reaching $91.5 \%$. The WTP also increased by 2797.9 JPY ( $p<.10$, Cohen's $\mathrm{d}=.21)$. In group C, with the loss-framed message, the WTP increased by 3361.8 JPY ( $p<.05$, Cohen's $\mathrm{d}=.23$ ) compared to the control group, reaching 3789 JPY. This was almost nine times higher than that of the control group, at 427.1 JPY. However, these messages did not have any promoting effect on the young with lower vaccination intentions at baseline.

Table 1 shows the messages' effects, using regression analysis and controlling for the influence of the attribute variables in Section 3.4. According to columns 1 and 2, the promoting effects for older adults changed little in magnitude and statistical significance (in order: $6 \%$, $p<.05$, Cohen's $\mathrm{d}=.18 ; 2304.7 \mathrm{JPY}, p<.10$, Cohen's $\mathrm{d}=.17 ; 3421.8$ JPY, $p<.05$, Cohen's $\mathrm{d}=.23$ ).

Furthermore, we changed the WTP variable into the following two variables. The first changed negative WTP values (below 0 JPY) to $0 \mathrm{JPY}$, and then focused on positive WTP values in the payment setting. The second changed positive WTP values (over $0 \mathrm{JPY}$ ) to $0 \mathrm{JPY}$ and focused on negative WTP values in the receipt setting. Using the first enabled us to determine the messages' effects on the vaccination intentions of those who already intended to receive the free vaccine and vice versa. Our estimation used the Tobit model here because the threshold of 0 JPY biases OLS estimates. The marginal effects are reported in columns $3,4,7$, and 8 .

The results showed that, for older respondents, the influence-gain nudge had the effect of increasing the intentions of those who did not yet intend to receive the free vaccine, while the loss-framed nudge further strengthened the intentions of the other subgroup with originally higher intentions. A new finding was that the comparison nudge had the same impact as the loss-framed message (1148.9 JPY, $p<.01$ ). The null hypothesis that the comparison nudge's effect was equal to the lossframed message's was not rejected $(p=.47)$. The failure to find the promoting effect of the comparison nudge in Fig. 3 and column 2 of Table 1 could be because this message possibly worked to weaken the intentions of those who did not intend to receive the free vaccine $(-522.81 \mathrm{JPY}, p=.49)$.

Among the older and young adults, annual household income raised WTP in the payment setting. Among the older adults, women were more likely to express a higher WTP. Both results were similar with those in the recent global survey on COVID-19 vaccines (Lazarus et al., 2021).

\subsection{Effects on autonomy and emotional burden}

We presented the levels of autonomy and emotional burden in the control group. The mean levels of voluntary, forced, distressed, should be improved were 3.69, 2.63, 2.31, 2.81 among older respondents and 3.04, $2.95,2.40,2.78$ among the young, respectively. The differences in voluntary and forced among the two generations were significant (p. $<01)$, implying that older adults were more likely to feel their 

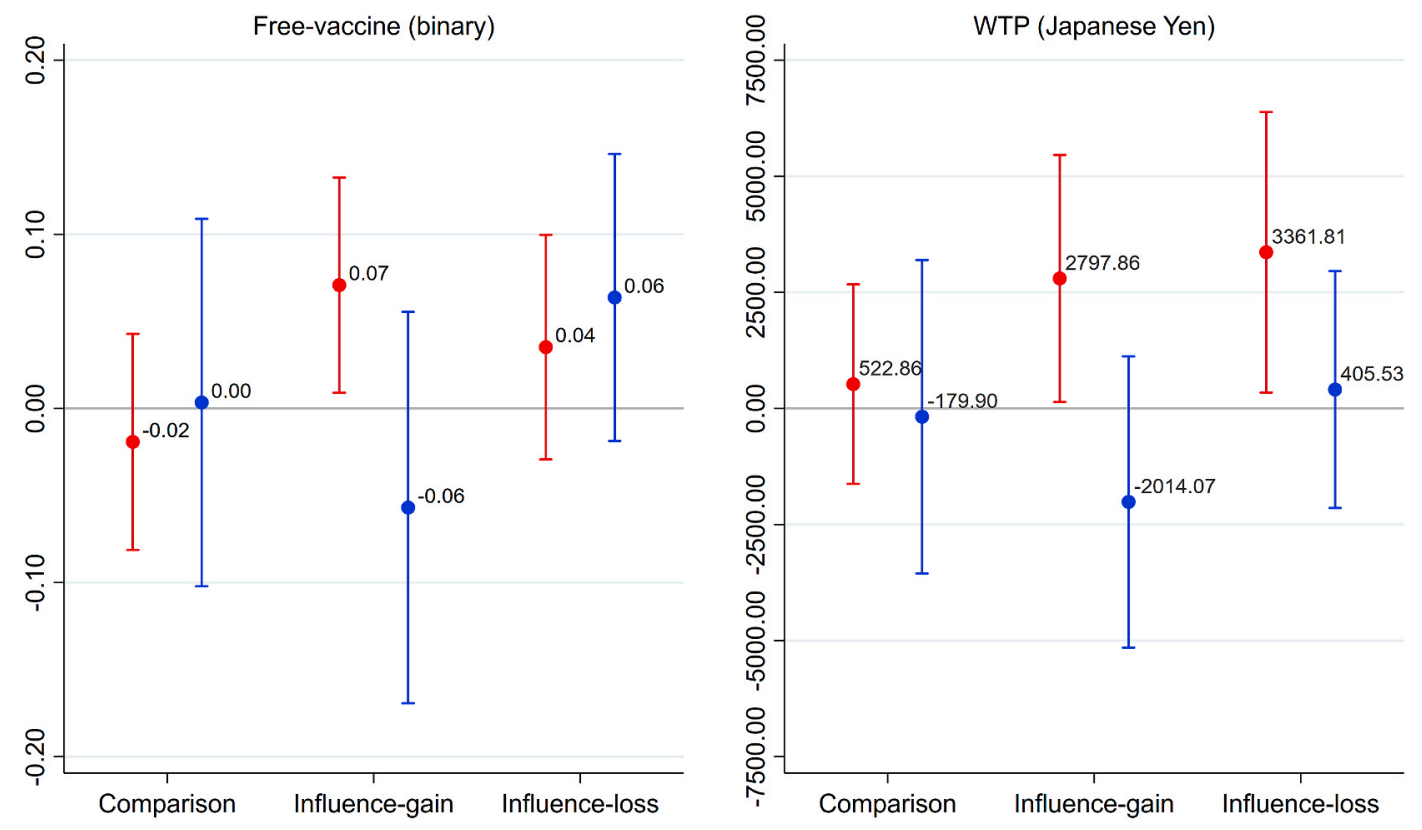

Old (65-74 years) $\quad$ Young (25-34 years)

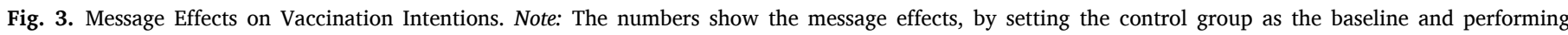
regression analysis without any covariates, while the bars show the $95 \%$ confidence interval.

Table 1

Message effects on vaccination intentions.

\begin{tabular}{|c|c|c|c|c|c|c|c|c|c|}
\hline & & (1) & (2) & (3) & (4) & (5) & (6) & (7) & (8) \\
\hline & & \multicolumn{4}{|c|}{ Older respondents (65-74 years) } & \multicolumn{4}{|c|}{ Young respondents (25-34 years) } \\
\hline & \multirow{2}{*}{$\frac{\text { Number of observations: }}{\text { Estimation method: }}$} & \multicolumn{4}{|l|}{798} & \multicolumn{4}{|l|}{797} \\
\hline & & \multicolumn{2}{|l|}{ OLS } & \multicolumn{2}{|l|}{ Tobit model } & \multicolumn{2}{|l|}{ OLS } & \multicolumn{2}{|c|}{ Tobit model } \\
\hline & \multirow[t]{2}{*}{ Dependent variable: } & Free-vaccine & WTP & WTP & WTP & Free-vaccine & WTP & WTP & WTP \\
\hline & & (binary) & (both) & (payment) & (receipt) & (binary) & (both) & $\overline{\text { (payment) }}$ & (receipt) \\
\hline Treatment A & Comparison & $\begin{array}{l}-0.02 \\
(0.03)\end{array}$ & $\begin{array}{l}619.73 \\
(1050.78)\end{array}$ & $\begin{array}{l}1148.86^{* * *} \\
(331.96)\end{array}$ & $\begin{array}{l}-522.81 \\
(756.07)\end{array}$ & $\begin{array}{l}-0.01 \\
(0.05)\end{array}$ & $\begin{array}{l}-520.41 \\
(1771.62)\end{array}$ & $\begin{array}{l}-153.12 \\
(424.23)\end{array}$ & $\begin{array}{l}-215.40 \\
(1425.63)\end{array}$ \\
\hline Treatment B & Influence-gain & $\begin{array}{l}0.06^{* *} \\
(0.03)\end{array}$ & $\begin{array}{l}2304.71^{*} \\
(1211.43)\end{array}$ & $\begin{array}{l}726.14 \\
(628.11)\end{array}$ & $\begin{array}{l}1881.86^{* *} \\
(870.34)\end{array}$ & $\begin{array}{l}-0.07 \\
(0.06)\end{array}$ & $\begin{array}{l}-2306.11 \\
(1542.04)\end{array}$ & $\begin{array}{l}-312.45 \\
(487.84)\end{array}$ & $\begin{array}{l}-1908.36 \\
(1279.23)\end{array}$ \\
\hline Treatment C & Influence-loss & $\begin{array}{l}0.04 \\
(0.03)\end{array}$ & $\begin{array}{l}3421.82^{* *} \\
(1534.04)\end{array}$ & $\begin{array}{l}1754.17^{* *} \\
(702.35)\end{array}$ & $\begin{array}{l}990.35 \\
(851.27)\end{array}$ & $\begin{array}{l}0.06 \\
(0.04)\end{array}$ & $\begin{array}{l}291.57 \\
(1352.10)\end{array}$ & $\begin{array}{l}114.94 \\
(363.58)\end{array}$ & $\begin{array}{l}1180.14 \\
(1158.64)\end{array}$ \\
\hline Female (dummy) & & $\begin{array}{l}-0.02 \\
(0.03)\end{array}$ & $\begin{array}{l}172.69 \\
(854.34)\end{array}$ & $\begin{array}{l}735.68^{* *} \\
(292.68)\end{array}$ & $\begin{array}{l}-497.02 \\
(789.29)\end{array}$ & $\begin{array}{l}0.02 \\
(0.03)\end{array}$ & $\begin{array}{l}-596.43 \\
(1299.69)\end{array}$ & $\begin{array}{l}-127.65 \\
(386.91)\end{array}$ & $\begin{array}{l}154.35 \\
(888.16)\end{array}$ \\
\hline Educational years & & $\begin{array}{l}0.01 \\
(0.01)\end{array}$ & $\begin{array}{l}520.91 * \\
(280.91)\end{array}$ & $\begin{array}{l}191.77^{*} \\
(108.48)\end{array}$ & $\begin{array}{l}200.02 \\
(211.09)\end{array}$ & $\begin{array}{l}0.02^{*} \\
(0.01)\end{array}$ & $\begin{array}{l}422.09 \\
(375.92)\end{array}$ & $\begin{array}{l}151.27 \\
(107.85)\end{array}$ & $\begin{array}{l}359.84 \\
(237.69)\end{array}$ \\
\hline $\begin{array}{l}\text { Household annual income } \\
\text { (Unit: } 10 \text { thousand yen) }\end{array}$ & & $\begin{array}{l}-0.00 \\
(0.00)\end{array}$ & $\begin{array}{l}0.76 \\
(2.27)\end{array}$ & $\begin{array}{l}1.59^{* *} \\
(0.77)\end{array}$ & $\begin{array}{l}-0.76 \\
(1.28)\end{array}$ & $\begin{array}{l}0.00^{*} \\
(0.00)\end{array}$ & $\begin{array}{l}1.48 \\
(1.74)\end{array}$ & $\begin{array}{l}1.00^{* *} \\
(0.46)\end{array}$ & $\begin{array}{l}2.03 \\
(1.68)\end{array}$ \\
\hline Other attribute varibales & & YES & YES & YES & YES & YES & YES & YES & YES \\
\hline
\end{tabular}

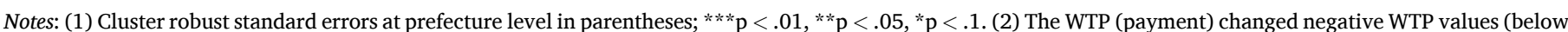

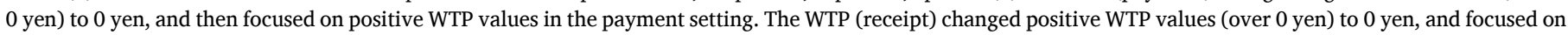

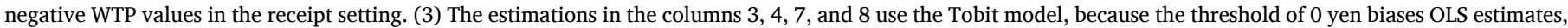
and the marginal effects are reported there.

autonomous decision-making was respected when they read explanations and messages on the vaccine compared to the young adults at baseline.

Table 2 shows the messages' effects on the secondary outcomes, using regression analysis and controlling for the covariates. The influence-loss nudge worsened the levels of autonomy and emotional burden compared to the control group among both the older and young respondents. This message increased the level of distressed among older respondents by 0.17 ( $p<.05$, Cohen's $\mathrm{d}=.17$ ) and the levels of forced and should be improved among young respondents by $0.42(p<.01$,
Cohen's $\mathrm{d}=.35$ ) and 0.37 ( $p<.01$, Cohen's $\mathrm{d}=.33$ ), respectively.

The influence-loss nudge made the older feel distressed. This message could strengthen their vaccination intentions but increase their stress, which may inhibit future and other cooperative behaviors, given the literature on nudges with negative emotions. This loss-framed message also made the young feel that they were forced to receive the vaccine and the explanation should be improved. It did not have any promoting effect for vaccination intentions, on average, but produced the side effects, which may reduce their cooperation for several infection control measures, not just vaccination. 
Table 2

Message effects on autonomy and emotional burden.

\begin{tabular}{|c|c|c|c|c|c|c|c|c|c|}
\hline \multirow{4}{*}{$\begin{array}{l}\text { Estimation method: } \\
\text { OLS }\end{array}$} & & (1) & (2) & (3) & (4) & (5) & (6) & (7) & (8) \\
\hline & & \multicolumn{4}{|c|}{ Older respondents (65-74 years) } & \multicolumn{4}{|c|}{ Young respondents (25-34 years) } \\
\hline & \multirow{2}{*}{$\begin{array}{l}\text { Number of observations: } \\
\text { Dependent variable (5-point } \\
\text { scale): }\end{array}$} & \multicolumn{4}{|l|}{798} & \multicolumn{4}{|l|}{797} \\
\hline & & voluntary & forced & distressed & $\begin{array}{l}\text { should be } \\
\text { improved }\end{array}$ & voluntary & forced & distressed & $\begin{array}{l}\text { should be } \\
\text { improved }\end{array}$ \\
\hline Treatment A & Comparison & $\begin{array}{l}-0.02 \\
(0.10)\end{array}$ & $\begin{array}{l}-0.09 \\
(0.09)\end{array}$ & $\begin{array}{l}0.04 \\
(0.10)\end{array}$ & $\begin{array}{l}0.06 \\
(0.11)\end{array}$ & $\begin{array}{l}-0.11 \\
(0.15)\end{array}$ & $\begin{array}{l}0.01 \\
(0.11)\end{array}$ & $\begin{array}{l}0.08 \\
(0.11)\end{array}$ & $\begin{array}{l}0.08 \\
(0.11)\end{array}$ \\
\hline Treatment B & Influence-gain & $\begin{array}{l}0.10 \\
(0.13)\end{array}$ & $\begin{array}{l}-0.06 \\
(0.16)\end{array}$ & $\begin{array}{l}0.07 \\
(0.10)\end{array}$ & $\begin{array}{l}0.05 \\
(0.12)\end{array}$ & $\begin{array}{l}-0.20 \\
(0.14)\end{array}$ & $\begin{array}{l}-0.01 \\
(0.09)\end{array}$ & $\begin{array}{l}0.10 \\
(0.09)\end{array}$ & $\begin{array}{l}0.14 \\
(0.09)\end{array}$ \\
\hline Treatment C & Influence-loss & $\begin{array}{l}0.09 \\
(0.11)\end{array}$ & $\begin{array}{l}0.08 \\
(0.13)\end{array}$ & $\begin{array}{l}0.17^{* * *} \\
(0.07)\end{array}$ & $\begin{array}{l}0.14 \\
(0.10)\end{array}$ & $\begin{array}{l}0.01 \\
(0.13)\end{array}$ & $\begin{array}{l}0.42^{* * *} \\
(0.10)\end{array}$ & $\begin{array}{l}0.18 \\
(0.11)\end{array}$ & $\begin{array}{l}0.37 * * * \\
(0.10)\end{array}$ \\
\hline Attribute variables & & YES & YES & YES & YES & YES & YES & YES & YES \\
\hline
\end{tabular}

Note: Cluster robust standard errors at prefecture level in parentheses; ${ }^{* * *} \mathrm{p}<.01,{ }^{* *} \mathrm{p}<.05,{ }^{*} \mathrm{p}<.1$.

Because of their high lethality rate, older adults would have likely experienced significant pressure from society and their communities to receive the COVID-19 vaccine. The loss-framed nudge with threatening language may have intensified the interpersonal and intrapersonal pressure, making older people behave as if they place a high value on the vaccine. In addition, COVID-19 vaccination was not a priority for younger adults in Japan's initial vaccination program. In that situation, pressuring them to be vaccinated with the loss-framed message may have only increased negative emotions.

At the end of this experiment, we conducted debriefing, offered respondents an opportunity to change their vaccination decision, but confirmed that few of them changed the decision (Please see Appendix Table C).

\subsection{Further analysis}

Brewer et al. (2011) reported that the positive correlation between vaccination intention and behavior was solid especially among those who did not want to be vaccinated. In other words, many people who say they will not receive vaccines in advance will not do so in practice. We checked the robustness of the nudges' effects by using another binary variable indicating that people will not receive the COVID-19 vaccine even when they can obtain the maximum amount of 30,000 JPY for their vaccination (Appendix Table D). As reference information, we also presented an estimation result using the opposite binary variable, which indicated that people will receive it even when they need to pay 30,000 JPY.

The results showed the influence-gain nudge reduced the proportion of the older respondents who would not receive the vaccine even when they could obtain $30,000 \mathrm{JPY}$, by $4 \%(p<.05)$. This nudge could reduce the number of people who were most likely to avoid vaccination, further supporting the nudge's effectiveness. Additionally, the comparison nudge and the influence-loss one increased the proportion of those who would receive it even when they pay 30,000 JPY, by $4-5 \%$ (at least, $p<$ $.05)$. These results were consistent with those of the primary analysis. On the contrary, the influence-gain nudge might increase the proportion of young respondents who would not receive the vaccine even when they could obtain the maximum money amount $(p<.10)$. This analysis also presented the possibility that the same nudge may have opposite effects across generations.

What generates differences in the nudges' effects between older and young respondents? The baseline WTP may be a factor because it is higher in the older than in the young respondents, as already shown. The severity of COVID-19 was also higher in older respondents, and thus it may be another factor. In other words, we may find some promoting effects of nudges among young respondents who feel they are at high risk for severe disease, as do older respondents.

Our experiment's question ascertained respondents' subjective probability of becoming severely ill and suffering severe sequelae if they became infected with COVID-19. On average, the probability was higher in older respondents $(41.40 \%)$ than in young respondents $(26.47 \%, p<$ .01). In Appendix Table E, we used its median value (15.00\%), divided the young respondents into two sub-groups, and estimated the nudges' effects. The results showed that the influence-loss nudge increased the proportion of those receiving the free vaccine and the WTP levels among those with a higher probability. As in older respondents, the nudge was effective among young respondents with a high probability of severe disease. On the other hand, it was not among the other sub-group, and thus it had no facilitating effect on the average.

\section{Discussion and limitations}

\subsection{Discussion}

Our online experiment suggested that other-regarding messages had the following effects on COVID-19 vaccination intentions. First, the influence-gain nudge increased the proportion of older adults who would receive the vaccine if offered for free. Second, the vaccination intentions of older adults who already intended to receive it were further strengthened because of the loss-framed nudge and the comparison nudge. However, the former message placed an emotional burden on viewers. Third, these messages did not have any promoting effect for young adults with lower vaccination intentions at baseline.

The result that the loss-framed message was more emotionally burdensome than the gain-framed one is consistent with that of the COVID-19 social distancing study (Heffner et al., 2020). As in the study conducted in other countries (Moehring et al., 2021), the comparison nudge will work in Japan. This nudge was also not emotionally burdensome on average but may further weaken the intentions of older adults who did not intend to receive the vaccine. This study's finding on the comparison nudge supports the possibility that this nudge has both of a facilitating effect and a free-riding effect.

Our findings suggested that governments should use different messages depending on purposes and targets. First, the gain-framed nudge will be effective for increasing the number of older adults who newly decide to receive the vaccine. One option is to include this message on public posters and websites. Second, the comparison nudge will be effective for reinforcing the intentions of older adults who have already intended to receive the vaccine and ensuring their vaccination is carried out. Regarding social well-being, the governments should use the comparison nudge, instead of the loss-framed nudge that has the similar promoting effect but increases the emotional burden of the viewers. However, since the comparison nudge may further weaken the vaccination intentions of older adults with originally lower intentions, it is necessary to display this message only to those who wish to get vaccinated. One option is to include this message on the reservation screen for vaccinations or in reminder e-mails.

Our messages had some promoting effects for the older generation, 
but not for the younger one, on average. This difference may be due to various factors, including differences in the level of vaccination intention at baseline, the risk of severe disease, and the priorities in the actual vaccination program.

The risk of severe COVID-19 disease is higher in the older than in the young. If the risk among the older gets lowered, there will be more hospital beds for other patients with severe diseases, contributing to the sustainability of the healthcare delivery system. In this sense, it is essential to make the vaccination uptake rate among the older generation closer to $100 \%$ from a policy perspective. On the other hand, it is also crucial to increase the percentage of young people who wish to receive the vaccine for society to acquire herd immunity.

Further analysis showed that the influence-loss nudge increased the willingness to receive the free vaccine and WTP among young respondents with a higher subjective risk of severe disease. Discovering effective messages for each sub-group and tailoring personalized messages is one strategy for this generation. WTP provides another insight: it tells us how many people are willing to receive the vaccine when offered at a specific price. In other words, it tells us what price (or subsidy) governments need to put on the vaccine to ensure a certain target rate. The influence-gain nudge increased the proportion of older adults willing to receive the free vaccine by around $6 \%$. The control group in Appendix Table A shows that a subsidy of 2000 JPY to 4000 JPY for vaccinations is needed to increase the proportion of the young willing to receive the vaccine by similar percentages. Using financial incentives is another strategy, as studies have already started to examine its effect (Campos-Mercade et al., 2021).

\subsection{Limitations and future research directions}

This study had one limitation that our primary outcomes were intentions, not behaviors. The intention-behavior gap has also been reported in the vaccination context (see the review by Brewer et al., 2017). Its causes include supply-side factors, including vaccine shortages and procedural barriers, and demand-side factors, including forgetfulness and procrastination. On the other hand, this point does not deny that having a firm vaccination intention is necessary for vaccination implementation. Even if the barriers were removed but if people do not intend to receive the vaccine, they will not get vaccinated. Intentions have positive correlations with behaviors (Webb and Sheeran, 2006), and Brewer et al. (2011) found a similar trend in vaccinations. Additionally, the purpose of this study was to discover other-regarding nudges that could promote vaccinations while simultaneously considering viewers' autonomy and emotional burden. We believe that using intentions to test effects was reasonable under this objective before testing effects with actions. Of course, future research will need to test whether the comparison nudge and the influence-gain nudge, as recommended by this study, promote vaccination uptake.

As we explained in Section 3.3.1, this study's WTP may be underreported by the fact that the COVID-19 vaccine was offered free of charge in reality, which is another limitation of this study. We need to carefully consider this possibility when interpreting the WTP values. In addition, in this study, we created these questions to ascertain autonomous decision-making and emotional burden regarding nudges. Future research will need to develop more valid and general indicators.

Furthermore, future research will need to test whether this study's results can be applied to other countries and cultures. In general, Japanese people have a lower trust level for vaccines on an international scale (De Figueiredo et al., 2020). Additionally, they have long been considered to be collectivist (Hofstede, 1980), although this view has been re-examined (Takano and Osaka, 1999). The effects of other-regarding nudges may depend on these characteristics, and we may not observe a similar tendency in different cultures, including western societies. However, since the COVID-19 vaccination is being promoted worldwide, our findings could contribute to countries and cultures that share common characteristics with Japan.

\section{Conclusions}

Despite the limitations, this study makes significant academic and policy contributions, because it is one of the first to explore desirable nudge-based messages in the context of the COVID-19 vaccination, considering not only vaccination intentions but also autonomy and emotional burden. COVID-19 vaccination is still underway globally, and our findings can contribute to the improvement of the vaccination programs. Furthermore, our findings will have implications for vaccination programs under future pandemics.

\section{Credit author statement}

Shusaku Sasaki: Conceptualization, Methodology, Formal Analysis, Investigation, Data Curation, Writing - Original Draft, Writing - Review \& Editing, Visualization, Funding Acquisition. Tomoya Saito: Conceptualization, Methodology, Investigation, Writing - Review \& Editing. Fumio Ohtake: Conceptualization, Methodology, Investigation, Resources, Writing - Review \& Editing, Supervision, Project Administration, Funding Acquisition.

\section{Ethics approval}

We obtained ex-ante approval from the ethics committee of Graduate School of Economics, Osaka University. We also registered the experimental design with the AEA RCT Registry (Sasaki, Ohtake and Saito, 2021; https://doi.org/10.1257/rct.7361-1.1)

\section{Declaration of competing interest}

We declare no conflicts of interest.

\section{Acknowledgement}

The authors thank Ichiro Kawachi, S.V. Subramanian, and four anonymous referees for their insightful and detailed suggestions. This research was financially supported by the Japan Society for the Promotion of Science [JSPS Grant Numbers: 19K13722 (S., Sasaki) and 20H05632 (F., Ohtake)] and Japan Science and Technology Agency [JST PRESTO Grant Number: JPMJPR21R4 (S., Sasaki)]. Also, this research was conducted as a part of the research at the Research Institute of Economy, Trade and Industry (RIETI). JSPS, JST, and RIETI had no role in study design, data collection and analysis, decision to publish or preparation of the manuscript.

\section{Appendix U. Supplementary data}

Supplementary data to this article can be found online at https://doi.org/10.1016/j.socscimed.2021.114561. 


\section{Appendix}

Table A

Distributions of Willingness to Pay for Vaccine

\begin{tabular}{|c|c|c|c|c|c|c|c|c|c|c|c|c|c|c|c|c|c|}
\hline \multirow[t]{5}{*}{ WTP } & & \multicolumn{8}{|c|}{ Older respondents (65-74 years) } & \multicolumn{8}{|c|}{ Young respondents (25-34 years) } \\
\hline & & \multicolumn{2}{|c|}{ Control } & \multirow{2}{*}{\multicolumn{2}{|c|}{$\frac{\text { Treatment A }}{\text { Comparison }}$}} & \multirow{2}{*}{\multicolumn{2}{|c|}{$\frac{\text { Treatment B }}{\text { Influence-gain }}$}} & \multirow{2}{*}{\multicolumn{2}{|c|}{$\frac{\text { Treatment C }}{\text { Influence-loss }}$}} & \multicolumn{2}{|c|}{ Control } & \multirow{2}{*}{\multicolumn{2}{|c|}{$\frac{\text { Treatment A }}{\text { Comparison }}$}} & \multirow{2}{*}{\multicolumn{2}{|c|}{$\frac{\text { Treatment B }}{\text { Influence-gain }}$}} & \multirow{2}{*}{\multicolumn{2}{|c|}{$\frac{\text { Treatment C }}{\text { Influence-loss }}$}} \\
\hline & & & & & & & & & & & & & & & & & \\
\hline & & \multicolumn{2}{|c|}{$\mathrm{N}=199$} & \multicolumn{2}{|c|}{$\mathrm{N}=200$} & \multicolumn{2}{|c|}{$\mathrm{N}=200$} & \multicolumn{2}{|c|}{$\mathrm{N}=199$} & \multicolumn{2}{|c|}{$\mathrm{N}=200$} & \multicolumn{2}{|c|}{$\mathrm{N}=199$} & \multicolumn{2}{|c|}{$\mathrm{N}=199$} & \multicolumn{2}{|c|}{$\mathrm{N}=199$} \\
\hline & & Freq. & Percent & Freq. & Percent & Freq. & Percent & Freq. & Percent & Freq. & Percent & Freq. & Percent & Freq. & Percent & Freq. & Percent \\
\hline \multirow[t]{9}{*}{ Payment setting } & 35000 & 6 & $3.02 \%$ & 15 & $7.50 \%$ & 9 & $4.50 \%$ & 17 & $8.54 \%$ & 2 & $1.00 \%$ & 4 & $2.01 \%$ & 5 & $2.51 \%$ & 3 & $1.51 \%$ \\
\hline & 25000 & 1 & $0.50 \%$ & 0 & $0.00 \%$ & 1 & $0.50 \%$ & 0 & $0.00 \%$ & 1 & $0.50 \%$ & 0 & $0.00 \%$ & 0 & $0.00 \%$ & 1 & $0.50 \%$ \\
\hline & 17500 & 4 & $2.01 \%$ & 4 & $2.00 \%$ & 2 & $1.00 \%$ & 3 & $1.51 \%$ & 4 & $2.00 \%$ & 3 & $1.51 \%$ & 1 & $0.50 \%$ & 1 & $0.50 \%$ \\
\hline & 12500 & 6 & $3.02 \%$ & 16 & $8.00 \%$ & 11 & $5.50 \%$ & 15 & $7.54 \%$ & 8 & $4.00 \%$ & 2 & $1.01 \%$ & 10 & $5.03 \%$ & 4 & $2.01 \%$ \\
\hline & 9000 & 9 & $4.52 \%$ & 7 & $3.50 \%$ & 10 & $5.00 \%$ & 6 & $3.02 \%$ & 6 & $3.00 \%$ & 3 & $1.51 \%$ & 7 & $3.52 \%$ & 4 & $2.01 \%$ \\
\hline & 6500 & 29 & $14.57 \%$ & 24 & $12.00 \%$ & 29 & $14.50 \%$ & 31 & $15.58 \%$ & 22 & $11.00 \%$ & 24 & $12.06 \%$ & 16 & $8.04 \%$ & 30 & $15.08 \%$ \\
\hline & 4000 & 55 & $27.64 \%$ & 44 & $22.00 \%$ & 57 & $28.50 \%$ & 54 & $27.14 \%$ & 46 & $23.00 \%$ & 52 & $26.13 \%$ & 34 & $17.09 \%$ & 41 & $20.60 \%$ \\
\hline & 2000 & 30 & $15.08 \%$ & 35 & $17.50 \%$ & 36 & $18.00 \%$ & 31 & $15.58 \%$ & 22 & $11.00 \%$ & 27 & $13.57 \%$ & 29 & $14.57 \%$ & 35 & $17.59 \%$ \\
\hline & 500 & 28 & $14.07 \%$ & 20 & $10.00 \%$ & 28 & $14.00 \%$ & 18 & $9.05 \%$ & 23 & $11.50 \%$ & 19 & $9.55 \%$ & 20 & $10.05 \%$ & 27 & $13.57 \%$ \\
\hline \multirow[t]{9}{*}{ Receipt setting } & -500 & 0 & $0.00 \%$ & 1 & $0.50 \%$ & 1 & $0.50 \%$ & 1 & $0.50 \%$ & 9 & $4.50 \%$ & 3 & $1.51 \%$ & 7 & $3.52 \%$ & 4 & $2.01 \%$ \\
\hline & -2000 & 1 & $0.50 \%$ & 0 & $0.00 \%$ & 0 & $0.00 \%$ & 1 & $0.50 \%$ & 2 & $1 \%$ & 2 & $1.01 \%$ & 2 & $1.01 \%$ & 0 & $0.00 \%$ \\
\hline & -4000 & 2 & $1.01 \%$ & 1 & $0.50 \%$ & 1 & $0.50 \%$ & 3 & $1.51 \%$ & 5 & $2.50 \%$ & 7 & $3.52 \%$ & 7 & $3.52 \%$ & 4 & $2.01 \%$ \\
\hline & -6500 & 0 & $0.00 \%$ & 0 & $0.00 \%$ & 0 & $0.00 \%$ & 0 & $0.00 \%$ & 3 & $1.50 \%$ & 2 & $1.01 \%$ & 0 & $0.00 \%$ & 0 & $0.00 \%$ \\
\hline & -9000 & 4 & $2.01 \%$ & 2 & $1.00 \%$ & 2 & $1.00 \%$ & 1 & $0.50 \%$ & 9 & $4.50 \%$ & 12 & $6.03 \%$ & 12 & $6.03 \%$ & 6 & $3.02 \%$ \\
\hline & -12500 & 0 & $0.00 \%$ & 0 & $0.00 \%$ & 0 & $0.00 \%$ & 0 & $0.00 \%$ & 0 & $0.00 \%$ & 0 & $0.00 \%$ & 2 & $1.01 \%$ & 2 & $1.01 \%$ \\
\hline & -17500 & 1 & $0.50 \%$ & 1 & $0.50 \%$ & 1 & $0.50 \%$ & 0 & $0.00 \%$ & 1 & $0.50 \%$ & 6 & $3.02 \%$ & 1 & $0.50 \%$ & 4 & $2.01 \%$ \\
\hline & -25000 & 1 & $0.50 \%$ & 1 & $0.50 \%$ & 0 & $0.00 \%$ & 3 & $1.51 \%$ & 8 & $4 \%$ & 5 & $2.51 \%$ & 5 & $2.51 \%$ & 7 & $3.52 \%$ \\
\hline & -35000 & 22 & $11.06 \%$ & 29 & $14.50 \%$ & 12 & $6.00 \%$ & 15 & $7.54 \%$ & 29 & $14.50 \%$ & 28 & $14.07 \%$ & 41 & $20.60 \%$ & 26 & $13.07 \%$ \\
\hline
\end{tabular}

Table B

Descriptive Statistics

\begin{tabular}{|c|c|c|c|c|c|c|c|c|c|}
\hline \multirow[t]{5}{*}{ Variables: } & & (1) & (2) & (3) & (4) & (5) & (6) & (7) & (8) \\
\hline & & \multicolumn{4}{|c|}{ Old respondents (65-74 years) } & \multicolumn{4}{|c|}{ Young respondents (25-34 years) } \\
\hline & & \multirow[t]{2}{*}{ Control } & \multirow{2}{*}{$\frac{\text { Treamet A }}{\text { Comparison }}$} & \multirow{2}{*}{$\begin{array}{l}\text { Treamet B } \\
\begin{array}{l}\text { Influence- } \\
\text { gain }\end{array}\end{array}$} & \multirow{2}{*}{$\begin{array}{l}\text { Treamet C } \\
\text { Influence- } \\
\text { loss }\end{array}$} & \multirow[t]{2}{*}{ Control } & Treamet A & Treamet B & \multirow{2}{*}{$\begin{array}{l}\text { Treamet C } \\
\text { Influence- } \\
\text { loss }\end{array}$} \\
\hline & & & & & & & Comparison & $\begin{array}{l}\text { Influence- } \\
\text { gain }\end{array}$ & \\
\hline & $\begin{array}{l}\text { Number of } \\
\text { observations }=\end{array}$ & 199 & 200 & 200 & 199 & 200 & 199 & 199 & 199 \\
\hline \multirow[t]{2}{*}{ Age } & Mean & 68.95 & 69.22 & 69.33 & 68.95 & 29.97 & 30.19 & 30.40 & 30.39 \\
\hline & S.D. & 2.79 & 2.72 & 2.81 & 2.82 & 2.67 & 2.75 & 2.68 & 2.89 \\
\hline \multirow[t]{2}{*}{ Female (dummy) } & Mean & 0.50 & 0.50 & 0.50 & 0.50 & 0.50 & 0.50 & 0.50 & 0.50 \\
\hline & S.D. & 0.50 & 0.50 & 0.50 & 0.50 & 0.50 & 0.50 & 0.50 & 0.50 \\
\hline \multirow[t]{2}{*}{ Married (dummy) } & Mean & 0.82 & 0.80 & 0.84 & 0.80 & 0.37 & 0.40 & 0.40 & 0.41 \\
\hline & S.D. & 0.38 & 0.40 & 0.37 & 0.40 & 0.48 & 0.49 & 0.49 & 0.49 \\
\hline \multirow[t]{2}{*}{ Divorce/Bereavement (dummy) } & Mean & 0.13 & 0.15 & 0.09 & 0.14 & 0.02 & 0.02 & 0.01 & 0.01 \\
\hline & S.D. & 0.33 & 0.36 & 0.29 & 0.34 & 0.12 & 0.12 & 0.10 & 0.07 \\
\hline \multirow{2}{*}{$\begin{array}{l}\text { Number of family members living } \\
\text { together }\end{array}$} & Mean & 2.45 & 2.52 & 2.52 & 2.52 & 3.11 & 2.98 & 3.02 & 2.92 \\
\hline & S.D. & 1.08 & 1.17 & 1.02 & 0.94 & 1.53 & 1.28 & 1.45 & 1.42 \\
\hline \multirow{2}{*}{$\begin{array}{l}\text { Family members living together aged } \\
65 \text { or older (dummy) }\end{array}$} & Mean & 0.69 & 0.72 & 0.71 & 0.69 & 0.21 & 0.13 & 0.18 & 0.16 \\
\hline & S.D. & 0.46 & 0.45 & 0.46 & 0.46 & 0.40 & 0.34 & 0.39 & 0.37 \\
\hline \multirow[t]{2}{*}{ Educational years } & Mean & 14.14 & 14.17 & 14.20 & 14.07 & 14.67 & 14.79 & 14.86 & 14.77 \\
\hline & S.D. & 2.10 & 2.07 & 1.99 & 2.02 & 2.05 & 1.87 & 2.16 & 2.21 \\
\hline \multirow{2}{*}{$\begin{array}{l}\text { Annual household income (Unit: } 10 \\
\text { thousand yen) }\end{array}$} & Mean & 539.95 & 541.25 & 523.50 & 528.64 & 593.00 & 597.74 & 543.22 & 563.07 \\
\hline & S.D. & 373.05 & 381.40 & 340.89 & 354.39 & 350.52 & 297.69 & 288.14 & 326.61 \\
\hline \multirow[t]{2}{*}{ No income information (dummy) } & Mean & 0.22 & 0.20 & 0.14 & 0.17 & 0.22 & 0.18 & 0.14 & 0.20 \\
\hline & S.D. & 0.42 & 0.40 & 0.34 & 0.38 & 0.41 & 0.38 & 0.35 & 0.40 \\
\hline
\end{tabular}

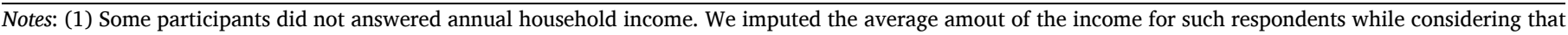

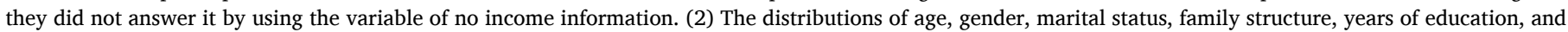

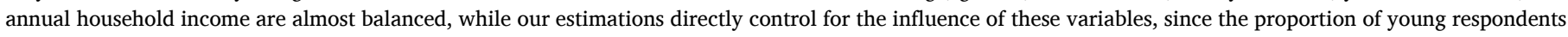

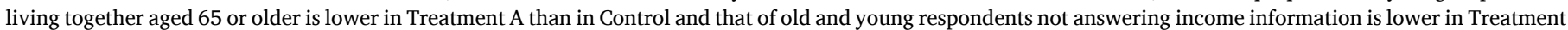

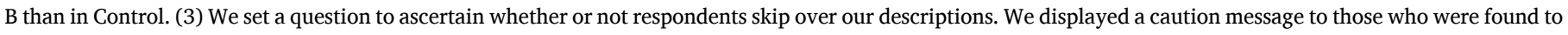
skip over them, while empirically controlling for them. 
Table C

Change in Decision

\begin{tabular}{|c|c|c|c|c|c|c|c|c|}
\hline & (1) & (2) & (3) & (4) & (5) & (6) & (7) & (8) \\
\hline & \multicolumn{4}{|c|}{ Old respondents (65-74 years) } & \multicolumn{4}{|c|}{ Young respondents (25-34 years) } \\
\hline & \multirow[t]{2}{*}{ Control } & \multirow{2}{*}{$\frac{\text { Treamet A }}{\text { Comparison }}$} & Treamet B & Treamet C & \multirow[t]{2}{*}{ Control } & Treamet A & Treamet B & Treamet C \\
\hline & & & Influence-gain & Influence-loss & & Comparison & Influence-gain & Influence-loss \\
\hline Number of observations $=$ & 199 & 200 & 200 & 199 & 200 & 199 & 199 & 199 \\
\hline \multirow[t]{2}{*}{ Change to "receive" } & 2 & 2 & 1 & 3 & 8 & 0 & 3 & 5 \\
\hline & $1.01 \%$ & $1.00 \%$ & $0.50 \%$ & $1.51 \%$ & $4.00 \%$ & $0.00 \%$ & $1.51 \%$ & $2.51 \%$ \\
\hline \multirow[t]{2}{*}{ No change } & 196 & 198 & 198 & 196 & 187 & 192 & 193 & 189 \\
\hline & $98.49 \%$ & $99.00 \%$ & $99.00 \%$ & $98.49 \%$ & $93.50 \%$ & $96.48 \%$ & $96.98 \%$ & $94.97 \%$ \\
\hline \multirow[t]{2}{*}{ Change to "do not receive" } & 1 & 0 & 1 & 0 & 5 & 7 & 3 & 5 \\
\hline & $0.50 \%$ & $0.00 \%$ & $0.50 \%$ & $0.00 \%$ & $2.50 \%$ & $3.52 \%$ & $1.51 \%$ & $2.51 \%$ \\
\hline
\end{tabular}

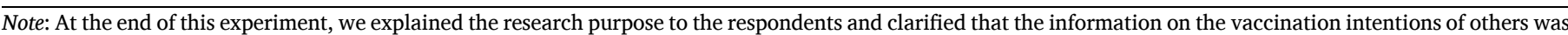

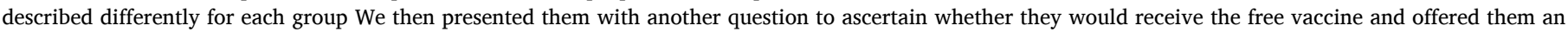

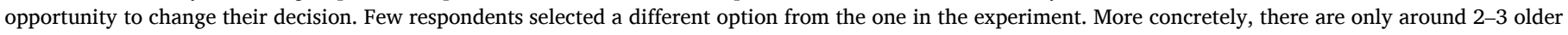
respondents in each group who switched and around 10 in each group for the younger population, with the numbers being similar between groups.

Table D

Further Analysis 1

\begin{tabular}{|c|c|c|c|c|c|}
\hline & & (1) & (4) & (5) & (8) \\
\hline & & \multicolumn{2}{|c|}{ Older respondents (65-74 years) } & \multicolumn{2}{|c|}{ Young respondents (25-34 years) } \\
\hline & Number of observations: & \multicolumn{2}{|l|}{798} & \multicolumn{2}{|l|}{797} \\
\hline & Estimation method: & \multicolumn{2}{|l|}{ OLS } & \multicolumn{2}{|l|}{ OLS } \\
\hline & Dependent variable: & minus 30,000 yen & plus 30,000 yen & minus 30,000 yen & plus 30,000 yen \\
\hline & & (binary) & (binary) & (binary) & (binary) \\
\hline Treatment A & Comparison & $\begin{array}{l}0.03 \\
(0.03)\end{array}$ & $\begin{array}{l}0.04 * * * \\
(0.01)\end{array}$ & $\begin{array}{l}0.00 \\
(0.04)\end{array}$ & $\begin{array}{l}0.01 \\
(0.01)\end{array}$ \\
\hline Treatment B & Influence-gain & $\begin{array}{l}-0.04^{* *} \\
(0.02)\end{array}$ & $\begin{array}{l}0.01 \\
(0.02)\end{array}$ & $\begin{array}{l}0.06^{*} \\
(0.03)\end{array}$ & $\begin{array}{l}0.02 \\
(0.01)\end{array}$ \\
\hline Treatment C & Influence-loss & $\begin{array}{l}-0.04 \\
(0.02)\end{array}$ & $\begin{array}{l}0.05^{* *} \\
(0.02)\end{array}$ & $\begin{array}{l}-0.01 \\
(0.03)\end{array}$ & $\begin{array}{l}0.00 \\
(0.01)\end{array}$ \\
\hline Attribute varibales & & YES & YES & YES & YES \\
\hline
\end{tabular}

Notes: (1) Cluster robust standard errors at prefecture level in parentheses; ${ }^{* * *} \mathrm{p}<.01$, ${ }^{* *} \mathrm{p}<.05$, *p $<.1$. (2) Minus 30,000 yen is one binary variable indicating that people will not receive the COVID-19 vaccine even when they can obtain the maximum amount of 30,000 yen for a vaccination. Plus 30,000 yen is another binary variable indicating that people will receive it even when they need to pay 30,000 yen.

Table E

Further analysis 2.

\begin{tabular}{|c|c|c|c|c|c|c|c|c|c|}
\hline & & (1) & (2) & (3) & (4) & (5) & (6) & (7) & (8) \\
\hline & & \multicolumn{4}{|c|}{$\begin{array}{l}\text { Young respondents with a lower subjective probability of } \\
\text { severe disease }\end{array}$} & \multicolumn{4}{|c|}{$\begin{array}{l}\text { Young respondents with a higher subjective probability of } \\
\text { severe disease }\end{array}$} \\
\hline & \multirow{2}{*}{$\frac{\text { Number of observations: }}{\text { Estimation method: }}$} & \multicolumn{4}{|l|}{417} & \multicolumn{4}{|l|}{380} \\
\hline & & \multicolumn{2}{|l|}{ OLS } & \multicolumn{2}{|c|}{ Tobit model } & \multicolumn{2}{|l|}{ OLS } & \multicolumn{2}{|c|}{ Tobit model } \\
\hline & Dependent variable: & Free-vaccine & WTP & WTP & WTP & Free-vaccine & WTP & WTP & WTP \\
\hline & & (binary) & (both) & (payment) & (receipt) & (binary) & (both) & (payment) & (receipt) \\
\hline Treatment A & Comparison & $\begin{array}{l}-0.05 \\
(0.08)\end{array}$ & $\begin{array}{l}-2336.92 \\
(2490.97)\end{array}$ & $\begin{array}{l}-697.26 \\
(582.80)\end{array}$ & $\begin{array}{l}-1491.07 \\
(2252.60)\end{array}$ & $\begin{array}{l}0.07 \\
(0.06)\end{array}$ & $\begin{array}{l}2473.35 \\
(2327.05)\end{array}$ & $\begin{array}{l}709.91 \\
(619.64)\end{array}$ & $\begin{array}{l}1745.34 \\
(1598.46)\end{array}$ \\
\hline Treatment B & Influence-gain & $\begin{array}{l}-0.09 \\
(0.07)\end{array}$ & $\begin{array}{l}-3391.68 \\
(2115.61)\end{array}$ & $\begin{array}{l}-570.77 \\
(574.26)\end{array}$ & $\begin{array}{l}-2644.14 \\
(1831.40)\end{array}$ & $\begin{array}{l}-0.01 \\
(0.07)\end{array}$ & $\begin{array}{l}-38.54 \\
(1918.60)\end{array}$ & $\begin{array}{l}242.79 \\
(591.46)\end{array}$ & $\begin{array}{l}-265.41 \\
(1352.69)\end{array}$ \\
\hline Treatment C & Influence-loss & $\begin{array}{l}-0.02 \\
(0.06)\end{array}$ & $\begin{array}{c}-2954.43 \\
(1891.11)\end{array}$ & $\begin{array}{l}-540.10 \\
(489.26)\end{array}$ & $\begin{array}{c}-1579.61 \\
(1685.57)\end{array}$ & $\begin{array}{l}0.17 * * * \\
(0.06)\end{array}$ & $\begin{array}{l}4786.85^{* *} \\
(2004.38)\end{array}$ & $\begin{array}{l}1033.77^{*} \\
(545.42)\end{array}$ & $\begin{array}{l}4973.68^{* * *} \\
(1524.84)\end{array}$ \\
\hline Attribute varibales & & YES & YES & YES & YES & YES & YES & YES & YES \\
\hline
\end{tabular}

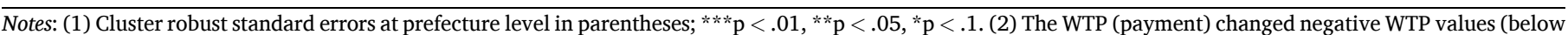

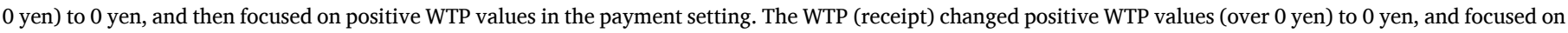

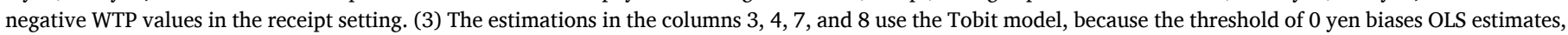

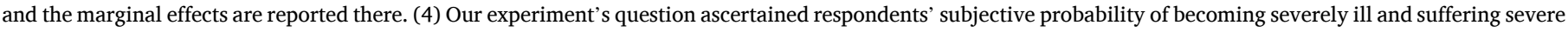

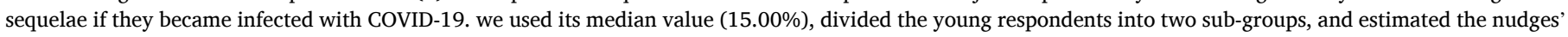
effects. 


\section{References}

Allcott, H., 2011. Social norms and energy conservation. J. Publ. Econ. 95 (9-10), 1082-1095.

Allcott, H., Kessler, J.B., 2019. The welfare effects of nudges: a case study of energy use social comparisons. Am. Econ. J. Appl. Econ. 11 (1), 236-276.

Andersen, S., Harrison, G.W., Lau, M.I., Rutström, E.E., 2006. Elicitation using multiple price list formats. Exp. Econ. 9 (4), 383-405.

Andreoni, J., 1990. Impure altruism and donations to public goods: a theory of warmglow giving. Econ. J. 100 (401), 464-477.

Becker, G.S., 1974. A theory of social interactions. J. Polit. Econ. 82 (6), 1063-1093.

Bénabou, R., Tirole, J., 2006. Incentives and prosocial behavior. Am. Econ. Rev. 96 (5), 1652-1678.

Berghea, F., Berghea, C.E., Abobului, M., Vlad, V.M., 2020. Willingness to Pay for a for a Potential Vaccine against SARS-CoV-2/COVID-19 Among Adult Persons. https://doi. org/10.21203/rs.3.rs-32595/v1 . Preprinr (Version 1) available at Research Square.

Bolino, M.C., 1999. Citizenship and impression management: good soldiers or good actors? Acad. Manag. Rev. 24 (1), 82-98.

Brewer, N.T., Gottlieb, S.L., Reiter, P.L., McRee, A.L., Liddon, N., Markowitz, L., Smith, J. S., 2011. Longitudinal predictors of human papillomavirus vaccine initiation among adolescent girls in a high-risk geographic area, 10.1097/OLQ.0b013e3181f12dbf Sex. Transm. Dis. 38, 197-204.

Brewer, N.T., Chapman, G.B., Rothman, A.J., Leask, J., Kempe, A., 2017. Increasing vaccination: putting psychological science into action. Psychol. Sci. Publ. Interest 18 (3), 149-207.

Campos-Mercade, P., Meier, A.N., Schneider, F.H., Meier, S., Pope, D., Wengström, E., 2021. Monetary incentives increase COVID-19 vaccinations. Science, eabm0475.

Capraro, V., Barcelo, H., 2020. The effect of messaging and gender on intentions to wear a face covering to slow down COVID-19 transmission. J. Beh. Econ. Policy. 4 (2), 45-55.

Centers for Disease Control and Prevention, 2021. How CDC is making COVID-19 vaccine recommendations. Available online: https://www.cdc.gov/coronavirus/2019-ncov/ vaccines/recommendations-process.html.

Cerda, A.A., García, L.Y., 2021. Willingness to pay for a COVID-19 vaccine. Appl. Health Econ. Health Pol. 19 (3), 343-351.

Chapman, G.B., Li, M., Leventhal, H., Leventhal, E.A., 2016. Default clinic appointments promote influenza vaccination uptake without a displacement effect. Beh. Sci. Policy. 2 (2), 40-50.

Chen, T., Dai, M., Xia, S., Zhou, Y., 2021. Do messages matter? Investigating the combined effects of framing, outcome uncertainty, and number format on COVID-19 vaccination attitudes and intention. Health Commun. 1-8. https://doi.org/10.1080/ 10410236.2021.1876814

Childress, J.F., Faden, R.R., Gaare, R.D., Gostin, L.O., Kahn, J., Bonnie, R.J., et al., 2002 Public health ethics: mapping the terrain. J. Law Med. Ethics 30 (2), 170-178.

Dai, H., Saccardo, S., Han, M.A., Roh, L., Raja, N., Vangala, S., et al., 2021. Behavioral nudges increase COVID-19 vaccinations. Nature 1-9.

Damgaard, M.T., Gravert, C., 2018. The hidden costs of nudging: experimental evidence from reminders in fundraising. J. Publ. Econ. 157, 15-26.

De Figueiredo, A., Simas, C., Karafillakis, E., Paterson, P., Larson, H.J., 2020. Mapping global trends in vaccine confidence and investigating barriers to vaccine uptake: a large-scale retrospective temporal modelling study. Lancet 396 (10255), 898-908.

Detweiler, J.B., Bedell, B.T., Salovey, P., Pronin, E., Rothman, A.J., 1999. Message framing and sunscreen use: gain-framed messages motivate beach-goers. Health Psychol. 18 (2), 189-196.

Deutch, M., Gerard, H.B., 1955. A study of normative and informational social influence upon judgment. J. Abnorm. Soc. Psychol. 51 (3), 629.

Fehr, E., Schmidt, K.M., 1999. A theory of fairness, competition, and cooperation. Q. J. Econ. 114 (3), 817-868.

Giubilini, A., 2021. Vaccination ethics. Br. Med. Bull. 137 (1), 4-12.

Glaeser, E.L., 2006. Paternalism and psychology. Univ. Chicago Law Rev. 73 (1), 133-156.

Hallsworth, M., List, J.A., Metcalfe, R.D., Vlaev, I., 2017. The behavioralist as tax collector: using natural field experiments to enhance tax compliance. J. Publ. Econ. 148, 14-31.

Hameleers, M., 2021. Prospect Theory in Times of a Pandemic: the Effects of Gain versus Loss Framing on Risky Choices and Emotional Responses during the 2020 Coronavirus Outbreak-Evidence from the US and the Netherlands. Mass Communication and Society, pp. 1-22.

Hanley, S.J., Yoshioka, E., Ito, Y., Kishi, R., 2015. HPV vaccination crisis in Japan. Lancet 385 (9987), 2571.

Heffner, J., Vives, M.L., FeldmanHall, O., 2020. Emotional responses to prosocial messages increase willingness to self-isolate during the COVID-19 pandemic. Pers. Individ. Pers. Individ. Differ. 170, 110420.

Hershey, J.C., Asch, D.A., Thumasathit, T., Meszaros, J., Waters, V.V., 1994. The roles of altruism, free riding, and bandwagoning in vaccination decisions. Organ. Behav. Hum. Decis. Process. 59, 177-187. https://doi.org/10.1006/obhd.1994.1055.

Hofstede, G., 1980. Culture's Consequences. Sage, Beverly Hills, CA.

Ibuka, Y., Li, M., Vietri, J., Chapman, G.B., Galvani, A.P., 2014. Free-riding behavior in vaccination decisions: an experimental study. PLoS One 9 (1), e87164.

Ikeda, S., Ueda, Y., Yagi, A., Matsuzaki, S., Kobayashi, E., Kimura, T., et al., 2019. HPV vaccination in Japan: what is happening in Japan? Expert Rev. Vacc. 18 (4), 323-325.

Japan Broadcasting Corporation, 2021. Number of COVID-19 infections in Japan (in Japanese)Available online: https://www3.nhk.or.jp/news/special/coronavirus/ data-all/.
Johnson, E.J., Goldstein, D., 2003. Do defaults save lives? Science 302 (5649), 1338-1340.

Jordan, J.J., Yoeli, E., Rand, D.G., 2021. Don’t get it or don’t spread it: comparing selfinterested versus prosocial motivations for COVID-19 prevention behaviors. Sci. Rep. 11 (1), 1-17.

Kahneman, D., Knetsch, J.L., Thaler, R.H., 1990. Experimental tests of the endowment effect and the Coase theorem. J. Polit. Econ. 98 (6), 1325-1348.

Kan, T., Zhang, J., 2018. Factors influencing seasonal influenza vaccination behaviour among elderly people: a systematic review. Publ. Health 156, 67-78.

Kelly, B.J., Hornik, R.C., 2016. Effects of framing health messages in terms of benefits to loved ones or others: an experimental study. Health Commun. 31 (10).

Korea Disease Control and Prevention Agency, 2021. Who gets vaccinated against COVID-19 first? Available online: https://ncv.kdca.go.kr/menu.es? mid=a101170 10000 .

Latkin, C.A., Dayton, L., Yi, G., Konstantopoulos, A., Boodram, B., 2021. Trust in a COVID-19 vaccine in the US: a social-ecological perspective. Soc. Sci. Med. 270, 113684.

Lazarus, J.V., Ratzan, S.C., Palayew, A., Gostin, L.O., Larson, H.J., Rabin, K., et al., 2021. A global survey of potential acceptance of a COVID-19 vaccine. Nat. Med. 27 (2), 225-228.

Loewenstein, G., O'Donoghue, T., 2006. We can do this the easy way or the hard way: negative emotions, self-regulation, and the law. Univ. Chicago Law Rev. 73 (1), 183-206.

Lunn, P.D., Timmons, S., Belton, C.A., Barjaková, M., Julienne, H., Lavin, C., 2020. Motivating social distancing during the Covid-19 pandemic: an online experiment. Soc. Sci. Med. 265, 113478.

Milkman, K.L., et al., 2021. A mega-study of text-based nudges encouraging patients to get vaccinated at an upcoming doctor's appointment. Proc. Natl. Acad. Sci. Unit. States Am. 118 (20), e2101165118.

Ministry of Health and Family Welfare, 2021. Near to home COVID vaccination centres (NHCVC) for elderly and differently abled citizens. Available online: https://www. mohfw.gov.in/pdf/GuidanceNeartoHomeCovidVaccinationCentresforElderlyandDi fferentlyAbledCitizens.pdf.

Ministry of Health, Labour and Welfare, 2021a. Information about COVID-19 vaccination (in Japanese)Available online: https://warp.da.ndl.go.jp/info:ndljp/pid/ 11669279/www.mhlw.go.jp/stf/seisakunitsuite/bunya/vaccine 00184.htmll.

Ministry of Health, Labour and Welfare, 2021b. Information about secureing the vaccination system for the COVID-19 vaccine (in Japanese)Available online: http s://www.med.or.jp/dl-med/kansen/novel_corona/vaccination/jichitai20210312_1. pdf.

Ministry of Internal Affairs and Communications, 2019. Report on the 2019 Survey of Telecommunications Usage Trends (Households) (in Japanese). Available online: https://www.soumu.go.jp/johotsusintokei/statistics/pdf/HR201900_001.pdf.

Miura, A., Kobayashi, T., 2019. Survey satisficing biases the estimation of moderation effects. Jpn. Psychol. Res. 61 (3), 204-210.

Moehring, A., Collis, A., Garimella, K., Rahimian, M.A., Aral, S., Eckles, D., 2021. Surfacing Norms to Increase Vaccine Acceptance (Pre-print).

Nafziger, J., 2020. Spillover effects of nudges. Econ. Lett. 190, 109086.

Nan, X., 2012a. Relative persuasiveness of gain-versus loss-framed human papillomavirus vaccination messages for the present-and future-minded. Hum. Commun. Res. 38 (1), 72-94. https://doi.org/10.1111/j.1468-2958.2011.01419.x.

Nan, X., 2012b. Communicating to young adults about HPV vaccination: consideration of message framing, motivation, and gender. Health Commun. 27 (1), 10-18. https:// doi.org/10.1080/10410236.2011.567447.

Ngo-Metzger, Q., August, K.J., Srinivasan, M., Liao, S., Meyskens Jr., F.L., 2008. End-oflife care: guidelines for patient-centered communication. Am. Fam. Physician 77 (2), $167-174$.

Ohtake, F., Sakata, K., Matsuo, Y., 2020. Early evacuation promotion nudges for heavy rain disasters. J. Behav. Econ. Fin. 13, 71-93.

Pittman, M., 2020. Accountability moderates the effects of egoistic and altruistic appeals in prosocial messages. J. Consum. Market. 37 (7), 807-820.

Prime Minister's Office, 2021. About the COVID-19 vaccine. Available online: https:// warp.da.ndl.go.jp/info:ndljp/pid/11656273/japan.kantei.go.jp/ongoingtopics/vacc ine.html.

Sasaki, S., Kurokawa, H., Ohtake, F., 2021a. Effective but fragile? Responses to repeated nudge-based messages for preventing the spread of COVID-19 infection. Jpn. Econ. Rev. 72, 371-408. https://doi.org/10.1007/s42973-021-00076-w.

Sasaki, S., Ohtake, F., Saito, T., 2021b. How to explain peer information: Nudging people to have a stronger intention to receive the COVID-19 vaccine. AEA RCT Registry. https://doi.org/10.1257/rct.7361-1.1.

Sasaki, S., Saito, T., Ohtake, F., 2021c. The Situation-dependency of Vaccination Intention: Policy Implications Based on Willingness-to-pay for the COVID-19 Vaccine, pp. 1-25. RIETI Discussion Paper Series.

Sato, R., Takasaki, Y., 2019. Peer effects on vaccination behavior: experimental evidence from rural Nigeria. Econ. Dev. Cult. Change 68 (1), 93-129.

Schneider, T.R., Salovey, P., Apanovitch, A.M., Pizarro, J., McCarthy, D., Zullo, J. Rothman, A.J., 2001. The effects of message framing and ethnic targeting on mammography use among low-income women. Health Psychol. 20 (4), 256-266.

Shang, J., Croson, R., 2009. A field experiment in charitable contribution: the impact of social information on the voluntary provision of public goods. Econ. J. 119 (540), 1422-1439.

Sheeran, P., Webb, T.L., 2016. The intention-behavior gap. Soc. Person. Psychol. Compass. 10 (9), 503-518.

Sunstein, C.R., 2020. Sludge audits. Behav. Public Policy 1-20.

Takano, Y., Osaka, E., 1999. An unsupported common view: comparing Japan and the US on individualism/collectivism. Asian J. Soc. Psychol. 2 (3), 311-341. 
Thaler, R.H., 2018. Nudge, not sludge, 431-431 Science 361 (6401).

Thaler, R.H., Sunstein, C.R., 2009. Nudge: Improving Decisions about Health, Wealth, and Happiness. Penguin.

The U.S. Food and Drug Administration, 2021. Fact sheet for healthcare providers administering vaccine (vaccination providers). Availabe online: https://www.fda. gov/media/144413/download.

Thunström, L., 2019. Welfare effects of nudges: the emotional tax of calorie menu labeling. Judg. Decis. Mak. 14 (1), 11.

Tregoning, J.S., Flight, K.E., Higham, S.L., Wang, Z., Pierce, B.F., 2021. Progress of the COVID-19 vaccine effort: viruses, vaccines and variants versus efficacy, effectiveness and escape. Nat. Rev. Immunol. 1-11.

Tversky, A., Kahneman, D., 1979. Prospect theory: an analysis of decision under risk. Econometrica 47 (2), 263-292.

Tversky, A., Kahneman, D., 1981. The framing of decisions and the psychology of choice. Science 211 (4481), 453-458.
Tversky, A., Kahneman, D., 1991. Reference theory of choice and exchange. Q. J. Econ. 1039-1061.

Tversky, A., Kahneman, D., 1992. Advances in prospect theory: cumulative representation of uncertainty. J. Risk Uncertain. 5, 297-323.

UK Government, 2021. UK COVID-19 vaccines delivery plan. Available online: https:// www.gov.uk/government/publications/uk-covid-19-vaccines-delivery-plan.

Webb, T.L., Sheeran, P., 2006. Does changing behavioral intentions engender behavior change? A meta-analysis of the experimental evidence. Psychol. Bull. 132 (2), 249.

Wong, L.P., Alias, H., Wong, P.F., Lee, H.Y., Abubakar, S., 2020. The use of the health belief model to assess predictors of intent to receive the COVID-19 vaccine and willingness to pay. Hum. Vaccines Immunother. 16 (9), 2204-2214.

Yan, H., Yates, J.F., 2019. Improving acceptability of nudges: learning from attitudes towards opt-in and opt-out policies. Judgm. Dec. Mak. 14 (1), 26. 